\title{
Analysis of hydrological changes and flood increase in Niamey based on the PERSIANN-CDR satellite rainfall estimate and hydrological simulations over the 1983-2013 period
}

\author{
C. Casse and M. Gosset \\ Géoscience Environnement Toulouse, Toulouse, France \\ Correspondence to: C. Casse (claire.casse@get.obs-mip.fr), M. Gosset (marielle.gosset@ird.fr)
}

Received: 12 March 2015 - Accepted: 12 March 2015 - Published: 11 June 2015

\begin{abstract}
A dramatic increase in the frequency and intensity of floods due to the Niger River in the city of Niamey (Niger) has been observed in the last decade. Previous studies highlighted the role of the land use changes on the flood increase since 1970s. In the last decade, observations have raised the issue of a possible increase in extreme rainfall in the Sahel, which may have caused the recent and extreme floods in Niamey in 2010, 2012 and 2013. The study focuses on the $125000 \mathrm{~km}^{2}$ basin between Ansongo and Niamey. This is the drainage area of the monsoon rainfall that leads to the rapid flow rise occurring between June and October. To understand the possible role of rainfall in flood intensification, satellite rainfall estimate is attractive in a region where the operational gauge network is sparse. This paper analyses the evolution of the Niger hydrograph in Niamey based on discharge observations, hydrological modelling and the satellite product PERSIANN-CDR, over the 1983-2013 period. PERSIANN-CDR is first compared with four other rainfall products. The salient features of the observed changes, i.e. a marked change in the mean decadal hydrograph, is well mimicked by the simulations, implying that rainfall is the first driver to the observed changes. The increase of flooded years over the period is also well reproduced but with some uncertainties in the exact number of flood days per year.
\end{abstract}

\section{Introduction}

The Tropics is a region of the world where global changes and the associated risks are increasing. The rising anthropic pressure, massive urbanization, land use changes and development of intensive agriculture are among the factors that increase the hydrological impacts of climate variability. In such a changing context, understanding and attributing the observed changes in the continental hydrological cycle is difficult. In many tropical regions, as in most African river basins, the sparseness of the observation network is an additional challenge.

The Niger is the main river running through West Africa. The upper part of the basin, between its source (situated in humid Guinea) and the city of Niamey, crosses a region which has seen major changes since the 1950s: the Sahel. This region has undergone one of the strongest climatic sig- nal ever recorded, with a period of dramatic droughts in the $70 \mathrm{~s}$ and the 80s. These sustained droughts had drastic consequences on the population, with many famines. The dramatic decrease in rainfall had also some irreversible (or at least long lasting) consequences on the eco-systems and on hydrological processes. Many studies have reported the so-called 'Sahelian paradox': decrease in rainfall but increase in runoff because of changing properties of the soil (soil crusting etc.). The latest rainfall records tend to show that the Sahel region is gradually recovering, since the late 90 s and that the annual rainfall amounts are getting back to the level they were before the 70s - at least in the Eastern part of the Sahel (Lebel and Ali, 2009). The recent years have also seen the occurrence of many floods in the Sahel and particularly in Niamey where the Niger River caused dramatic inundations in 2010, 2012 and 2013 (Sighomnou et al., 2013). 
Several studies based on the long series of river height data, available for the Niamey Niger station have analysed the changes in the hydrograph and the recent increase of floods (Descroix et al., 2012; Sighomnou et al., 2013). The river flow in Niamey exhibits two peaks. The first peak occurs between August and September and is due to the heavy monsoon rainfall occurring relatively close from Niamey (within a few hundred $\mathrm{km}$ ). The second and longer lasting peak, is due to the delayed arrival of water drained by the upper river basin. In the past, the two peaks used to be merged into a single one (Amani and Ngueta, 2002; Descroix et al., 2012). But since 1970s, the first peak gradually became distinct from the second, arguably because of the increase in runoff in the Sahelian zone (Albergel, 1987; Amani and Nguetora, 2002; Mahé and Paturel, 2009; Amogu et al., 2010; Descroix et al., 2012). Previous studies have highlighted the role of the land use changes. Land clearing and soil crusting lead to increase the runoff and the endoreic ruptures, which in turn caused an increase of the first peak in Niamey. In the last decade, these hydrological changes have become more dramatic with the occurrence of extreme floods. In 2010, 2012 and 2013 the discharge levels were the highest ever recorded since 1920s. In addition to land-use changes, recent observations have mentioned a possible increase in extreme rainfall in the Sahel (Panthou et al., 2014) which may had an important role in these extreme floods.

To study the inter-annual variability of the Niger floods in Niamey, understand their genesis and their recent increase, the hydrological response to rainfall variability must be analysed. Combining observations and hydrological modelling is a useful strategy to understand the sensitivity and test the impact of various factors or processes on the observed hydrological changes. The sparseness of the operational gauge network in the studied region makes satellite rainfall estimate attractive especially since the quality of these products have improved, and their usability for hydrology has been recognized (Bitew et Gebremichael, 2011; Thiemig et al., 2013; Gosset et al., 2013).

Casse et al. (2015) have already shown that satellite rainfall estimates associated with hydrological modelling could be a proxy to follow and diagnose the first flood in Niamey between 2000 and 2013. Here, the study is extended to a longer period (1983-2013) with the benefit of new data sets - both rainfall and discharge. The first objective is to analyse whether or not a hydrological model forced with a satellite rainfall product can reproduce the observed changes in the Niger Hydrograph in Niamey over the last 30 years. A further objective is to understand the detailed role of rainfall in the recent flood increase in Niamey.

\section{Methodology and data set}

The work is based on a long series of observations (discharge and rainfall) and the modelling set up introduced in Casse et

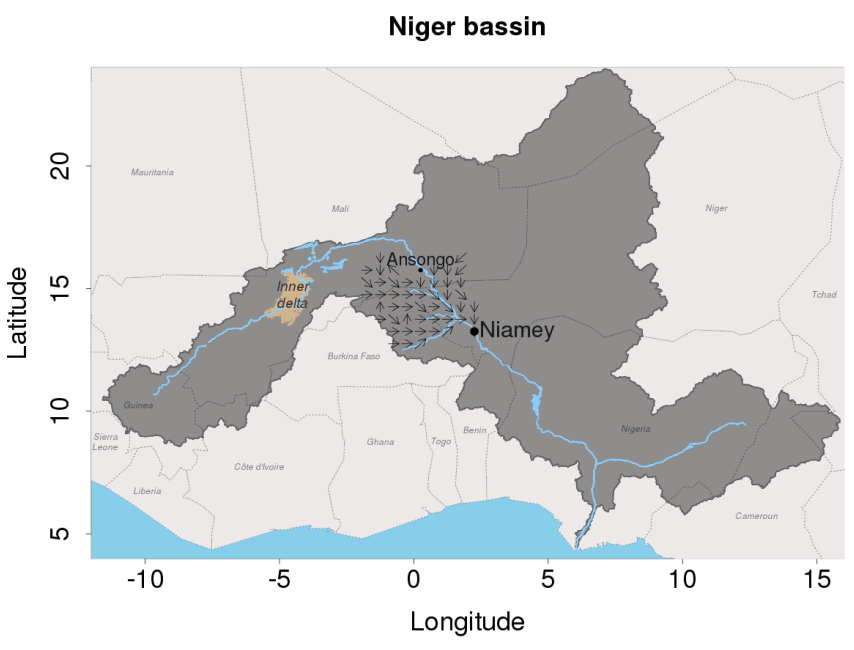

Figure 1. The Niger River basin, modified from Casse et al. (2015). The black arrows represent the stream flow direction in TRIP, for the 49 pixels of the hydrological modelling domain between Ansongo and Niamey.

al. (2015; C2015 here after). C2015 focused on the recent period (2000-2013) and tested 6 rainfall products as forcing. The aim was to assess the skill of model and satellite rainfall combination to simulate a realistic discharge and diagnose the occurrence of floods. Here, the aim is to analyse the hydrological changes over a longer period. The only satellite rainfall product with sufficient resolution $\left(0.5^{\circ}\right.$ or better; day or better) readily available over 30 years is the new Precipitation estimation from Remotely Sensed Information using Artificial Neural Network (PERSIANN): PERSIANN Climate Data Record or PERSIANN-CDR (Ashouri et al., 2014).

\subsection{Study area}

The study area consists in a $125000 \mathrm{~km}^{2}$ basin between Ansongo $\left(15^{\circ} 40^{\prime} \mathrm{N}, 0^{\circ} 30^{\prime} \mathrm{E}\right.$, Mali) and Niamey $\left(13^{\circ} 31^{\prime} \mathrm{N}\right.$, $2^{\circ} 6^{\prime} \mathrm{E}$, Niger) cities (Fig. 1). It is the drainage area of the rainfall monsoon causing the first flood in Niamey. Three right bank tributaries - the Gorouol, the Dargol and the Sirba - and smaller ephemeral rivers (called Kories) form the contributing part $\left(117610 \mathrm{~km}^{2}\right)$. During the monsoon season (June to September), heavy rainfall drained by these torrential regime tributaries lead to a quick rise of the water level in Niamey. This is called the "first" or "red" flood because of the colour of its sedimentary load. The left bank side of the study area is mainly endoreic, and does not contribute to the river flows. The "second" (or "white") flood occurs after the rainy season in Niamey (around January) and is caused by the late contribution of upper parts of the Niger basin. The focus here is solely on the first flood which has increased dramatically and reach historical levels in the last decade. 

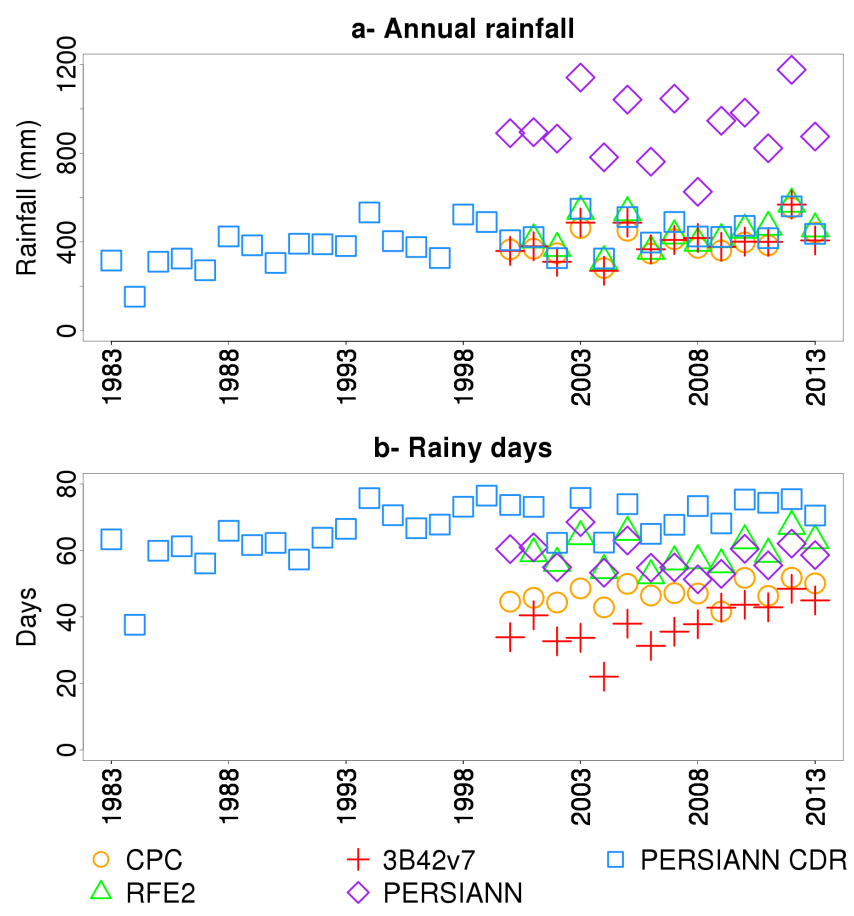

Figure 2. Annual rainfall accumulation (a) and number of rainy day (b) for PERSIANN-CDR (1983-2013) and other products (2000-2013) over the study region.

\subsection{Data}

\subsubsection{Discharge}

The daily discharge in Ansongo and Niamey (Fig. 1) station from 1983 to 2013 are provided by the Niger Basin Authority (NBA or ABN in French), which records the daily discharge in several stations of the Niger River. Ansongo is characterized by a single flood occurring around December or January. The delay for the flows between Ansongo and Niamey is around 1 day. Niamey is characterized by two floods, the "first" due to local monsoon rainfall and the "second" due to upper basin contribution. According to the NBA, the threshold of $530 \mathrm{~cm}$, equivalent to a river discharge of $1700 \mathrm{~m}^{3} \mathrm{~s}^{-1}$, is the critical height that triggers flooding in Niamey.

\subsubsection{Rainfall}

The main focus is on the analysis of the long term series based on PERSIANN-CDR (Ashouri et al., 2014). As PERSIANN-CDR is recent, no work has been reported yet on the validation of this product in Sahel. Figure 2 compares some characteristics of PERSIANN-CDR with 4 products that have been tested previously (Gosset al., 2013; Casse et al., 2015): (i) the gauge only product from the Climate Prediction Centre (CPC) (Xie and Arkin, 1997) (ii) the near real time satellite only product PERSIANN(Sorooshian et al., 2000) (iii) the global gauge adjusted satellite prod- uct from the Tropical Rain Measurement Mission (TRMM) Multi-platform Algorithm (TMPA) version 7, shortly named 3B42v7 (Huffman et al., 2007) and (iv) the regional gauge adjusted satellite product developed by the CPC, the African Rainfall Estimate (RFE2) (The NOAA Climate Prediction Centre, 2002). PERSIANN-CDR presents the same annual rainfall accumulation as 3B42v7, RFE2 or CPC (Fig. 2a). This product does not overestimate rainfall quantities as PERSIANN near real time product. However PERSIANNCDR produces the highest number of rainy days. As CPC or RFE2, PERSIANN-CDR tends to produce a lot of rainy days and spatially extended rainfall events with relatively small intensities, leading to smooth rain field.

\subsection{Hydrological modelling}

As in C2015, the hydrological simulation is based on the land surface model (LSM) ISBA (Interactions between Soil, Biosphere, and Atmosphere) coupled with the routing scheme TRIP (Total Runoff Integrating Pathways) within the SURFEX platform (www.cnrm.meteo.fr/surfex/, Masson et al., 2013) developed at MeteoFrance. ISBA-TRIP is a so called "physical based" and distributed model. In each grid cell $\left(0.5^{\circ} \times 0.5^{\circ}\right)$ ISBA evaluates the water balance and distributes the water in different reservoirs: surface, ground water, aquifers, and flood plains. Then TRIP routes the surface water into the hydrological channel and turns the water mass from ISBA into discharge. Vegetation and soil type are used to derive the ISBA parameters; orography and hydraulic equations are used to derive the TRIP network and parameters. The model forcing consists in:

- $3 \mathrm{~h}$ time step atmospheric data (exclusive of rainfall) based on 2002-2012 WATCH Forcing Data methodology applied to ERA-Interim data (WFDEI, Weedon et al., 2011) reanalysed by MeteoFrance. Sensitivity tests realised on the 2002-2012 period, show no significant difference in modelling results between the raw atmospheric forcing and its inter-annual mean. Based on these results the 2002-2012 inter-annual mean is used to force the model between 1983 and 2013 for the preliminary runs presented here.

- $3 \mathrm{~h}$ time step rainfall data based on PERSIANN-CDR (Sect. 2.2.2). PERSIANN-CDR is provided as a daily product. In the Sahel (Mathon et al., 2002) most of the rainfall is due to organized convection. The associated rain events at ground level have a typical duration of a few hours, with most of the rainfall brought by intense rain rates during the short lasting convective part (Mathon et al., 2002). In order to test the sensitivity of the simulations, two simple assumptions are tested: (i) the daily rainfall is uniformly distributed and (ii) the daily rainfall is assumed to have fallen within a single time step (in the 6th, 15:00 to 18:00 GMT). Note that 

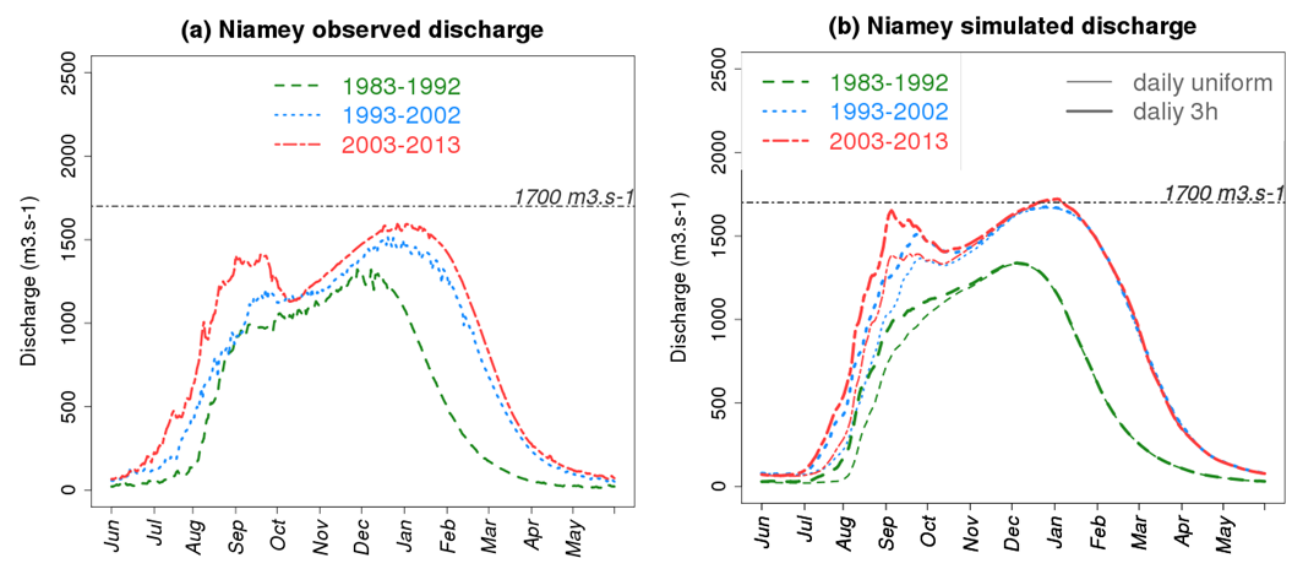

Figure 3. Mean observed (a) and simulated (b) discharge at Niamey station for 3 decades: 1983-1992 (green dashed line), 1993-2002 (blue dotted line) and 2003-2013 (red mix dashed line).

the second assumption is more consistent with the convective nature of Sahelian rainfall.

- Observed daily discharge at the entrance point of the simulated part of the Niger basin. As in C2015 only the Ansongo-Niamey reach is simulated and the model need to be constrained with the observed discharge at Ansongo (details in C2015).

The hydrological modelling domain (Fig. 1) covers 49 pixels $\left(0.5^{\circ} \times 0.5^{\circ}\right)$.

\section{Results}

\subsection{Observed changes}

Figure 2a displays the PERSIANN-CDR annual rainfall and number of rainy days over the studied region from 1983 to 2013. The series is consistent with the recent recovery of Eastern Sahel precipitation since the 90s compared to the 70s and 80s (Lebel and Ali, 2009). The PERSIANNCDR decadal mean increases from $327 \mathrm{~mm}$ (1983-1992), to $419 \mathrm{~mm}$ (1993-2002) and $455 \mathrm{~mm}$ (2003-2013); with a marked jump between the first and the second decade (Fig. 1a). Figure $2 b$ shows the mean annual number of rainy days. It rises between the first (59 days) and the second (71 days) decade, and stays quite steady for the last decade (71 days).

Figure $3 \mathrm{a}$ presents the observed changes in the mean decadal hydrograph over the 31 years studied period, divided in three decades: 1983-1992, 1993-2002 and 2003-2013 (11 years). The mean value of the first peak, changes from 1079 to $1412 \mathrm{~m}^{3} \mathrm{~s}^{-1}$ between the first and the last decade. The rise of the water level arises earlier, shifting from August to July over the 3 decades. Changes occur also in the second flood, where the maximum discharge changes from 1322 to $1594 \mathrm{~m}^{3} \mathrm{~s}^{-1}$, and shifts from December to January. Altogether both the discharge levels and the total length of the high water season have increased. The strongest change for the mean decadal first peak is between the second and third decade; for the second peak, the changes are more marked between the first and second decade. The reasons for these differences and their relation with the changes in rainfall over various parts of the basin would be worth exploring but is beyond the scope of the present study.

In addition to this mean increase in the first and second peak of the hydrograph, another phenomenon has been observed and is reported in Table 1: the first peak has been reaching extreme values and caused many floods in Niamey in the last decade. Table 1 (1st row) shows that only 1 flood occurred during the 1983-1992 decade, 2 during the 1993-2002 decade and 5 during the 2003-2013 period (4 for the 2003-2012 decade). C2015 and Fig. 2a show that the extremes floods are associated with relatively high rainfall amounts in the area.

\subsection{Hydrological simulations}

Figure $3 \mathrm{~b}$ shows the mean decadal simulated discharge in Niamey for the three decades: 1983-1992, 1993-2002 and 2003-2013 (11 years). Due to the restricted domain used for the simulation and because the discharge is constrained at the entrance of the domain, we concentrate the analysis on the first peak - the most directly influenced by the rain forcing over the domain. Both the simulation based on uniform rain within the day and the simulation with rainfall concentrated in one $3 \mathrm{~h}$ step, reproduce the change in the mean decadal peak. The shape of the peak is well reproduced by the " $3 \mathrm{~h}$ rain" simulation and too smooth for the daily uniform forcing. For the " $3 \mathrm{~h}$ rain" simulation the mean first peak increases from 1159 to $1652 \mathrm{~m}^{3} \mathrm{~s}^{-1}$ between the first and the last decade. This difference $\left(493 \mathrm{~m}^{3} \mathrm{~s}^{-1}\right)$ is higher than for the observations $\left(333 \mathrm{~m}^{3} \mathrm{~s}^{-1}\right)$. On the contrary the difference is smaller $\left(265 \mathrm{~m}^{3} \mathrm{~s}^{-1}\right)$ for the uniform rainfall simulation. These results highlight the sensitivity of the model to the 
Table 1. Observed and simulated flooding periods in day in Niamey between 1983 and 2013. Years in bold font correspond to observed floods. For simulations years in bold font and equal to 0 correspond to non-detection and years in normal font correspond to false-alarm.

\begin{tabular}{|c|c|c|c|c|c|c|c|c|c|c|c|c|}
\hline & 1988 & 1994 & 1998 & 1999 & 2003 & 2005 & 2006 & 2007 & 2008 & 2010 & 2012 & 2013 \\
\hline Observation & 16 & 1 & 9 & 0 & 14 & 0 & 2 & 0 & 0 & 7 and 12 & 42 & 14 \\
\hline Daily rainfall $\left(1700 \mathrm{~m}^{3} \mathrm{~s}^{-1}\right)$ & $\mathbf{0}$ & 28 & 23 & 0 & 32 & 0 & $\mathbf{0}$ & 0 & 0 & 8 & 17 & 5 \\
\hline $3 \mathrm{~h}$ rain $\left(1700 \mathrm{~m}^{3} \mathrm{~s}^{-1}\right)$ & $\mathbf{0}$ & 52 & 30 & 10 & 60 & 7 & $\mathbf{0}$ & 5 & 4 & 30 & 36 & 12 \\
\hline $3 \mathrm{~h}$ rain (97th percentile) & $\mathbf{0}$ & 30 & 20 & 2 & 35 & 0 & $\mathbf{0}$ & 0 & 0 & 6 & 16 & 8 \\
\hline
\end{tabular}

distribution of the rainfall within the day. PERSIANN-CDR smoothes rain fields (Sect. 2.2) and a uniform distribution of rainfall among the day increases this effect.

Figure $3 \mathrm{~b}$ also shows that the simulations reproduce well the observed changes in the timing of the high water season, with an earlier rise of the water, which shift from August to July.

Table 1 reports the number of flooded days per year (for the years where either the observations or the simulation detected a flood). For the simulations the flood threshold is defined either as the absolute threshold defined by NBA $1700 \mathrm{~m}^{3} \mathrm{~s}^{-1}$ (Sect. 2.2.1), or with the corresponding percentile (97th) for each simulated discharge series, as recommended in C2015. In terms of detecting whether or not a flood (of any period) occurred for a given year, the uniform rainfall based simulation performs well with only two misses in 1988 and 2006, and no false alarm. The results are similar for the absolute and for the percentile based (not shown) threshold. For the " $3 \mathrm{~h}$ rain" simulation, 1988 and 2006 are also missed. The false alarms are strongly dependent on the definition of the threshold: based on the $1700 \mathrm{~m}^{3} \mathrm{~s}^{-1}, 4$ years are falsely detected as flooded (1999, 2005, 2007, and 2008); based on the 97th percentile, only 1 year (1999) is falsely detected as flooded and only for a 2 day period. Given the total length of the studied period these detection scores are satisfactory. When the relative (percentile based) threshold is used, both the " $3 \mathrm{~h}$ rain" and the uniform daily rain simulations give similar detection rates over the 31 year period.

The simulations have more difficulties in reproducing the length of the flooded periods. All simulations overestimate the length of the flood period for the first 3 flood years of the period: 1994, 1998 and 2003. The " $3 \mathrm{~h}$ rain" simulation with the $1700 \mathrm{~m}^{3} \mathrm{~s}^{-1}$ threshold gives realistic flood length for the last 3 years (2010, 2012 and 2013); when the 97th percentile is applied, the flood length is underestimated for these years. C2015 concluded that the percentile based criteria worked best for the 2000-2013 period. A single percentile is not adequate for a longer period which includes drastic changes in the hyetograph. More work is needed to analyse the relative changes in the discharge frequency distribution between the 3 decades and the (in)consistency of these changes between the simulations and the observations. The comparison of the PERSIANN-CDR product with a ground reference, over the
30 years period is planned and will help verifying how steady the relative performance of the product itself is.

Figure 4 provides 4 illustrative examples of the simulated discharges, for 3 years where floods were observed and 1 non flood year. Despite the relatively coarse and simple model used, and the uncertainties in the observed rainfall, the simulated discharge are globally in good agreement with the observations (the Nash Sutscliffe Efficiency is 0.89 for the 31 year simulation). The performance varies from year to year. In 1988 (Fig. 4a) and in 2012 (Fig. 4c) the simulation underestimates the highest relative maximum, and in 1988 the flood is not detected (Table 1). As expected the underestimation is worse for the simulation based on a uniform daily rain. In 1998 (Fig. 4b) on the contrary, the shape of the sharpest peak is well reproduced (and the value slightly overestimated). Further investigation is needed to understand if these differences are due to the rain forcing or to a misrepresentation of some processes in the model. The uncertainty in the Ansongo discharge used as a constraint or punctual problems such as a dyke rupture may also explain some differences. It is noteworthy that for both 1988 (Fig. 4a) and 1998 (Fig. 4b), the weak discharge variations at the very beginning of the season (June and July) are not reproduced by the model, even though rainfall is present. This could indicate that the Hortonian runoff is not well accounted for in the model. Figure $4 \mathrm{~d}$ is an example of a non-flooded year where the rainfall and modelling system behaves well.

Figure 5 illustrates the ability of the simulation to reproduce the inter-annual variability of the first flood. The analysis is based on the inter-annual series of the observed and simulated maximum discharge peak of the first flood. Anomalies are computed in order to analyse the relative rather than absolute variations. For any variable $x$, defined over the period as a time series of observed $x_{i}$, the anomaly of $x$ for a given hydrological year $i$ is:

$A_{x i}=\frac{x_{i}-\bar{x}_{i}}{\sigma_{x i}}$

where $\bar{x}_{i}$ is the inter-annual mean, and $\sigma_{x i}$ is the standard deviation of the sample of $x$. When $A_{x i}$ is positive (/negative), the maximum discharge for the year $i$ is above (/under) the maximum discharge mean of the period. The correlation (Pearson) between the series of simulated and observed anomalies is 0.62 as indicated on the plot, showing that the series are in good agreement. For most years of the 1983- 

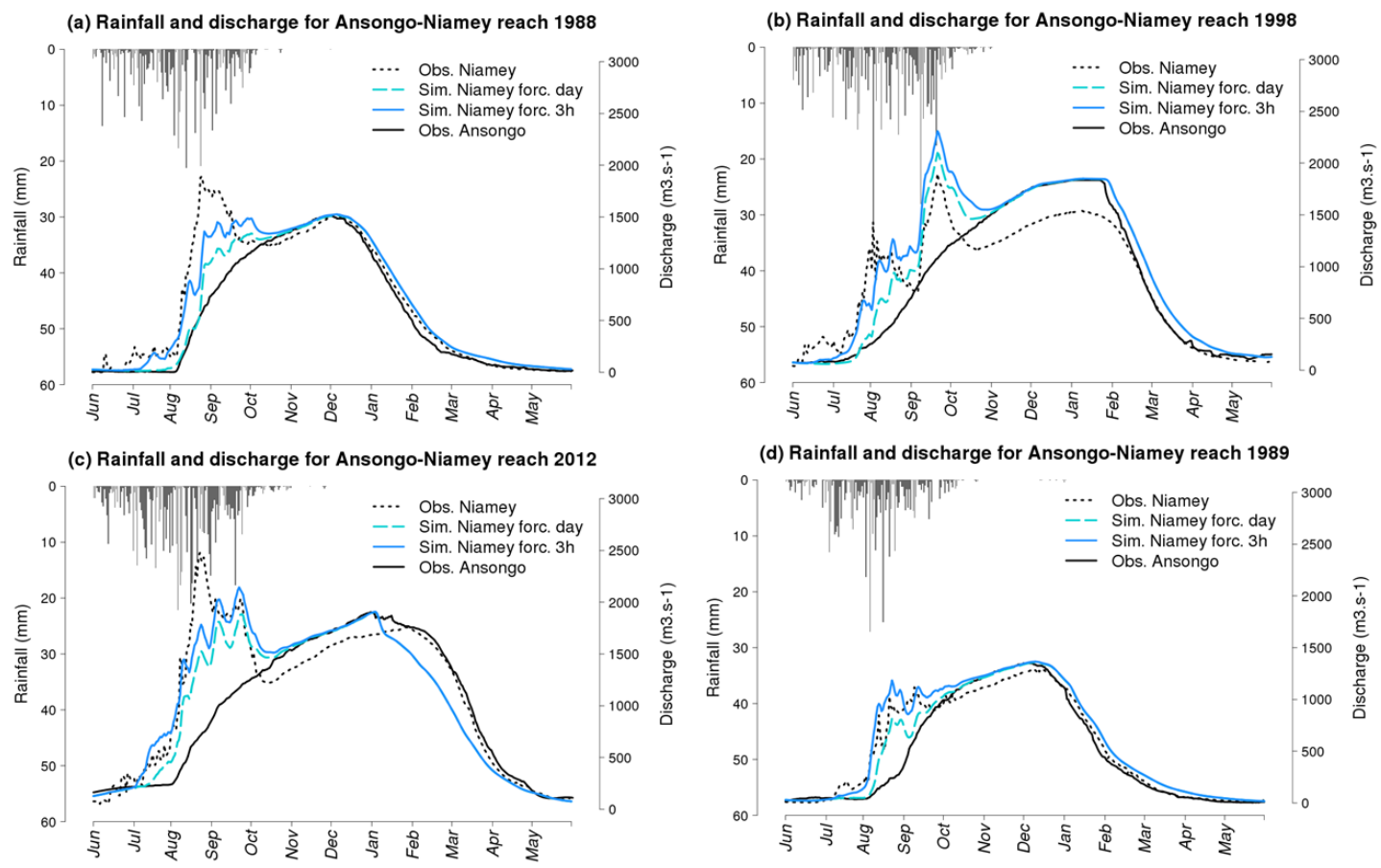

Figure 4. Mean daily rainfall on the study area (upper plot; solid grey bars), observed discharge in Ansongo (solid black line) and Niamey (dotted black line) and simulated discharge with uniform daily rainfall (dashed blue line) or $3 \mathrm{~h}$ rainfall (solid blue line); in 1988 (a), 1998 (b), 2012 (c) and 1989 (d).

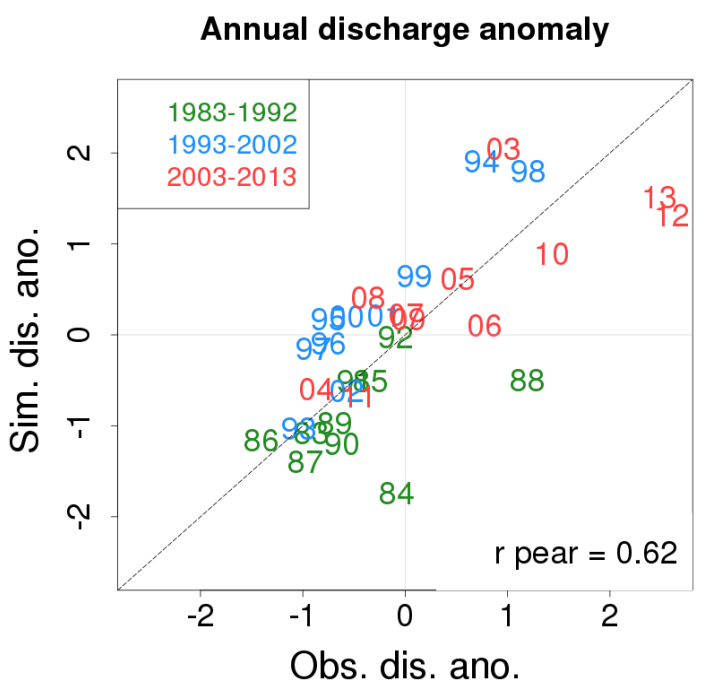

Figure 5. Scatter plot of the anomaly in the simulated peak discharge (Y) versus the anomaly in the observed peak discharge (X). The last 2 digits of the year are indicated for each dot (i.e. $12=2012$ ).

2013 period, the simulation is able to detect if the maximum discharge (for the first flood) should be considered as high or low compared to "normal" year. These results highlights the interest of using PERSIANN-CDR long series with hydrological modelling to analyse trends in flood occurrence.

\section{Conclusion and perspective}

- Over the study area (Sahel) PERSIANN-CDR produces annual rainfall amount comparable with those from gauge-adjusted satellite rainfall estimates (3B42v7, RFE2) and gauge products (CPC). As CPC and RFE2, PERSIANN-CDR smoothes the rain fields: a lot of rainy days with spatially extended events of weak intensity.

- Both uniform and non-uniform daily rainfall simulations reproduce the trend of the observed changes in the mean decadal hyetograph both in intensity and timing (Sect. 3.2). The simulated discharges are in good global agreement with the observations (NSE 0.89) but with some uncertainties, and a strong sensitivity to rainfall distribution within the day.

- The PERSIANN-CDR based hydrological simulation presents a realistic inter-annual variability, and detects flooded years, but not the exact flooded period day by day.

A relatively simple and coarse hydrological simulation, forced by a satellite rainfall product is able to reproduce the salient features of the changes in the average hydrograph of the Niger River, in Niamey, as observed over the last 30 years. This is quite remarkable, given the uncertainties associated with both the model and the satellite product. It is worth noting that the land use, soil properties, atmospheric 
forcing (other than rainfall) and other model parameters are held unchanged during this 31 year long simulation; only the rainfall forcing varies from year to year. Therefore the results show that rainfall variability can be considered as the main driver for the observed changes in the Niger hydrograph in Niamey.

More work is ongoing to study the changes over a longer period (from 1950) based on rain-gauges record. The sensitivity to the model parameters - and in particular land use and soil property changes- will be also tested. The conditions (on the discharge upstream of Niamey and on the rainfall in the area) that lead to flood, and their evolution over the decades will be analysed. It will be particularly interesting to assess if these conditions have changed between the 50-70s period (i.e before the long lasting droughts that impacted the Sahel in the late 70s and 80s) and the current period. If the rainfalldischarge relationship has changed, the reasons why should be investigated.

Acknowledgements. We warmly thank the Niger Basin Authority $(\mathrm{ABN})$, for providing the Niger River discharge data and for their collaboration. We are particularly very grateful to Bachir A. Tanimoun $(\mathrm{ABN})$. We would like also to thank all the team that provided the PERSIANN-CDR data sets online. This work has been cofunded by the French Centre National d'Etudes Spatiales (CNES) and the Midi-Pyrénées region.

\section{References}

Albergel, J.: Sécheresse, désertification et ressources en eau de surface - Application aux petits bassins du Burkina Faso, in: The Influence of Climate Change and Climatic Variability on the Hydrologic Regime and Water Resources, IAHS, Vancouver, 355365, 1987.

Amani, A. and Nguetora, M.: Evidence d'une modification du régime hydrologique du fleuve Niger à Niamey, in: 4th FRIEND 2002 - Regional Hydrology?: Bridging the Gap between Research and Practice, IAHS PUBLICATION, Cape Town, South Africa, 449-456, 2002.

Amogu, O., Descroix, L., Yéro, K. S., Le Breton, E., Mamadou, I., Ali, A., Vischel, T., Bader, J.-C., Moussa, I. B., Gautier, E., Boubkraoui, S., and Belleudy, P.: Increasing River Flows in the Sahel?, Water, 2, 170-199, doi:10.3390/w2020170, 2010.

Ashouri, H., Hsu, K.-L., Sorooshian, S., Braithwaite, D. K., Knapp, K. R., Dewayne Cecil, L., Nelson, B. R., and Prat, O. P.: PERSIANN-CDR: Daily Precipitation Climate Data Record from Multisatellite Observations for Hydrological and Climate Studies, B. Am. Meteor. Soc., 96, 69-83, doi:10.1175/BAMS-D13-00068.1, 2015.

Bitew, M. M. and Gebremichael, M.: Evaluation of satellite rainfall products through hydrologic simulation in a fully distributed hydrologic model, Water Resour. Res., 47, W06526. doi:10.1029/2010WR009917, 2011.
Casse, C., Gosset, G., Peugeot, C., Pedinotti, V., Boone, A., Tanimoun, B. A., and Decharme, B.: Potential of Satellite Rainfall Products to Predict Niger River Flood Events in Niamey, Atmos. Res., in press, doi:10.1016/j.atmosres.2015.01.010, 2015.

Descroix, L., Genthon, P., Amogu, O., Rajot, J.-L., Sighomnou, D., and Vauclin, M.: Change in Sahelian Rivers hydrograph: The case of recent red floods of the Niger River in the Niamey region, Global Plane. Change, 98-99, 18-30, doi:10.1016/j.gloplacha.2012.07.009, 2012.

Gosset, M., Viarre, J., Quantin, G., and Alcoba, M.: Evaluation of several rainfall products used for hydrological applications over West Africa using two high-resolution gauge networks, Q. J. Roy. Meteorol. Soc., 139, 923-940, doi:10.1002/qj.2130, 2013.

Huffman, G. J., Bolvin, D. T., Nelkin, E. J., Wolff, D. B., Adler, R. F., Gu, G., Hong, Y., Bowman, K. P., and Stocker, E. F.: The TRMM Multisatellite Precipitation Analysis (TMPA): Quasi-Global, Multiyear, Combined-Sensor Precipitation Estimates at Fine Scales, J. Hydrometeorol., 8, 38-55, doi:10.1175/JHM560.1, 2007.

Lebel, T. and Ali, A.: Recent trends in the Central and Western Sahel rainfall regime (1990-2007), J. Hydrol., 375, 52-64, doi:10.1016/j.jhydrol.2008.11.030, 2009.

Mahé, G. and Paturel, J.-E.: 1896-2006 Sahelian annual rainfall variability and runoff increase of Sahelian Rivers, Comptes Rend. Geosci., 341, 538-546, doi:10.1016/j.crte.2009.05.002, 2009.

Mathon, V., Laurent, H., and Lebel, T.: Mesoscale convective systems rainfall in the Sahel, J. Appl. Meteorol., 41, 1081-1092, 2002.

Panthou, G., Vischel, T., and Lebel, T.: Recent trends in the regime of extreme rainfall in the Central Sahel, Int. J. Climat., 34, 39984006, doi:10.1002/joc.3984, 2014.

Sighomnou, D., Descroix, L., Mahe, G., Moussa, I. B., Gautier, E., Mamadou, I., Vandervaere, J.-P., Bachir, T., Coulibaly, B., Rajot, J.-L., Issa, O. M., Dessay, N., Delaître, E., Maiga, O. F., Diedhiou, A., Panthou, G., Vischel, T., Yacouba, H., Karambiri, H., Paturel, J. E., Diello, P., Mougin, E., Kergoat, L., and Hiernaux, P.: La crue de 2012 à Niamey?: un paroxysme du paradoxe du Sahel?, Sécheresse, 24, 3-13, doi:10.1684/sec.2013.0370, 2013.

Sorooshian, S., Hsu, K. L., Gao, X., Gupta, H. V., Iman, B., and Braitwaite, D.: Evaluation of PERSIANN System SatelliteBased Estimates of Tropical Rainfall, B. Am. Meteorol. Soc., 81, 2035-2046, 2000.

Thiemig, V., Rojas, R., Zambrano-Bigiarini, M., and De Roo, A.: Hydrological evaluation of satellite-based rainfall estimates over the Volta and Baro-Akobo Basin, J. Hydrol., 499, 324-338, doi:10.1016/j.jhydrol.2013.07.012, 2013.

Weedon, G. P., Gomes, S., Viterbo, P., Shuttleworth, W. J., Blyth, E., Osterle, H., Adam, J. C., Belllouin, N., Boucher, O., and Best, M.: Creation of the WATCH Forcing data and its use to assess global and regional reference crop evaporation over land during the twentieth century, J. Hydrometerol. 12, 823-848, doi:10.1175/2011JHM1369.1, 2011.

Xie, P. and Arkin, P. A.: Global Precipitation: a 17-Years Monthly Analysis Based on Gauge Observations, Satellite Estimates, and Numerical Model Outputs, B. Am. Meteorol. Soc., 78, 25392558, 1997. 